\title{
Jane Austen e Midiatização:
}

\author{
uma análise da web série The Lizzie Bennet Diaries \\ a partir da perspectiva da codificação/decodificação
}

\begin{abstract}
Resumo: Este trabalho investiga a web série The Lizzie Bennet Diaries sob a perspectiva da codificação/decodificação (HALL, 2003). Com o objetivo de refletir sobre os processos de midiatização e a migração das narrativas clássicas para outros suportes, utilizou-se Calvino (2007), Barbosa (2012), Hepp e Hasebrink (2015). A partir da análise do episódio 84, observou-se que as potencialidades do meio online favorecem o surgimento de diferentes posições de decodificação dos discursos apresentados na série.

Palavras-chave: Codificação/Decodificação. Midiatização. Web série. The Lizzie Bennet Diaries.
\end{abstract}

\section{Jane Austen y Mediatización: un análisis de la web serie The Lizzie Bennet Diaries desde la perspectiva de la codificación/decodificación}

Resumen: Este trabajo investiga la web serie The Lizzie Bennet Diaries desde la perspectiva de la codificación/decodificación (HALL, 2003). Con el fin de reflexionar sobre los procesos de mediatización y la migración de los cuentos clásicos para otros medios, se utilizó Calvino (2007), Barbosa (2012), Hepp y Hasebrink (2015). A partir del análisis del episodio 84, se observó que el potencial del medio en línea favorece la aparición de diferentes posiciones de decodificación de los discursos que se presentan en la serie.

Palabras Clave: Codificación/Decodificación. Mediatización. Web serie. The Lizzie Bennet Diaries.

\section{Jane Austen and Mediatization: an analysis of The Lizzie Bennet Diaries web series from the perspective of coding/decoding}

Abstract: This work investigates The Lizzie Bennet Diaries web series from the perspective of the coding/decoding (HALL, 2003). In order to reflect on

\section{Giovana Montes Celinsk}

\footnotetext{
Jornalista e professora do curso de Jornalismo da Faculdade Secal. Doutoranda em Comunicação e Linguagens pela Universidade Tuiuti do Paraná (UTP). Mestre em Comunicação pela Universidade Federal do Paraná (UFPR).

Bacharel em Comunicação Social com habilitação em Jornalismo pela Universidade Estadual de Ponta Grossa (UEPG). Integrante do Grupo de Pesquisa Interações Comunicacionais, Imagens e Culturas Digitais - INCOM (UTP).
} 
the mediatization processes and the migration of the classic narratives to other media, Calvino (2007), Barbosa (2012), Hepp and Hasebrink (2015) were used. From an analysis of episode 84, it was observed that the potential of the online medium allows the emergence of different positions of decoding of the discourses presented in the series.

Keywords: Coding/Decoding. Mediatization. Web series. The Lizzie Bennet Diaries.

\section{Introdução}

Vive-se em um cotidiano midiatizado na contemporaneidade. Constantemente conectados em seus computadores e dispositivos móveis, os sujeitos compreendem o mundo a partir das mídias. Ao considerar os processos de midiatização, os meios potencializam mudanças na sociedade e na cultura, transformando a forma como os indivíduos interagem entre si. Ao refletir sobre esse contexto, indaga-se: como as narrativas dos clássicos literários são reapropriadas e decodificadas na atualidade?

Esse estudo apresenta as primeiras considerações de pesquisa em desenvolvimento de tese de doutoramento sobre o formato audiovisual 'web série literária', tratando-se de produções criadas especificamente para a internet, que apresentam releituras contemporâneas de clássicos da literatura. Esse trabalho investiga, a partir do método de pesquisa exploratória, o episódio 84 da web série The Lizzie Bennet Diaries, uma adaptação de Orgulho e Preconceito, livro escrito pela inglesa Jane Austen em 1813.

A web série analisada apresenta a história em diversos espaços da internet: o YouTube, o Twitter e o Tumblr, além de sites produzidos especialmente para o desenvolvimento da narrativa. Desta forma, são utilizados diversos meios e plataformas que transmitem conteúdos diferenciados da mesma história. Logo, as linhas narrativas que constituem a trama são complementares, possibilitando que os personagens contem a sua história em primeira mão, interagindo com outros personagens e com o público que acompanha a série.

The Lizzie Bennet Diaries é considerada a primeira do formato e marca o início do fenômeno das web séries literárias. O site norte-americano responsável pela produção e veiculação dessa primeira série, Pemberley Digital $^{2}$, já lançou outras quatro produções que seguem o mesmo formato. Além delas, outras web séries também surgiram, de grande a baixo orçamento, apresentando releituras das obras de William Shakespeare, J. M. Barrie e Charlotte Brontë (EPLEY, 2015).

Com o objetivo de investigar as diferentes posições de decodificação dos discursos apresentados na web série, é necessário contextualizar as práticas e processos comunicacionais que envolvem esse formato audiovisual. Ao considerar essa questão, o próximo tópico discute a relação entre as transformações das mídias e as mudanças na cultura e na sociedade, a partir da releitura contemporânea dos clássicos da literatura.
2 O site está disponível no link: http://www.pemberleydigital.com/. 


\section{$\gamma_{\text {Rizoma }}$}

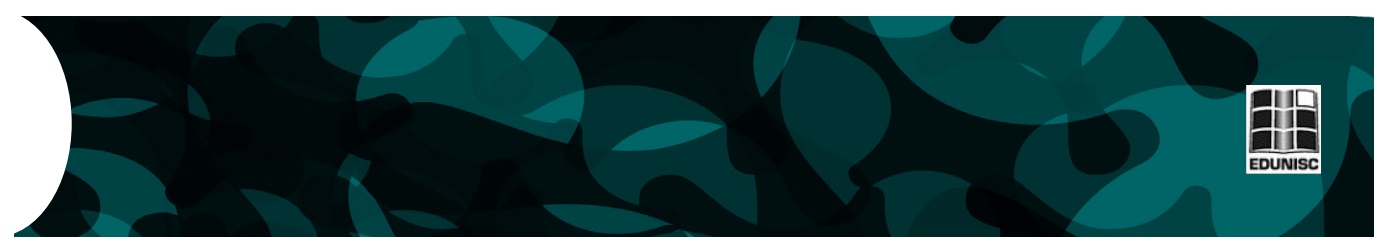

\section{0 clássico deslocado: processos de midiatização e transformações culturais}

As histórias clássicas da literatura acompanham a humanidade durante os séculos. Calvino (2007) ressalta que a longevidade dessas narrativas se dá devido a sua característica de universalidade: os clássicos situam os sujeitos no mundo. Desta forma, essas histórias acompanham gerações, pois carregam anseios, sentimentos e angústias que constituem o imaginário coletivo da humanidade.

Nota-se que os clássicos são tramas adoradas e reconhecidas pelos sujeitos, que se identificam com os personagens e "esperam" por cenas e momentos específicos da história. Essa estrutura básica do clássico precisa se manter a fim de que as releituras dessas narrativas em novos suportes possam ser reconhecidas como derivadas da trama original. Logo, ao investigar as narrativas clássicas em formatos contemporâneos, como a web série analisada The Lizzie Bennet Diaries, por exemplo, observa-se a importância de se refletir sobre o passado, pois os clássicos da literatura se caracterizam exatamente por permanecerem presentes (e relevantes) ao longo do tempo, diferentemente dos best sellers.

(...) o presente transforma-se no lugar natural da reflexão dos processos comunicacionais. É como se apenas o presente comportasse o ato comunicacional. Mas o que é objeto da reflexão da comunicação não é apenas o presente: deve ser o presente encharcado das práticas de comunicação. O que é objeto da comunicação são processos comunicacionais. E como pensar processos sem pensar em relação temporal? (BARBOSA, 2012, p. 2).

Ao investigar as narrativas clássicas em novos suportes, considera-se a perspectiva de Barbosa (2012) sobre a relevância do passado nos estudos do campo da comunicação. Cada época constrói práticas e processos comunicacionais que refletem o seu tempo (BARBOSA, 2012). Ao estudar os clássicos, é importante contextualizá-los como tramas atemporais, que carregam a cultura e os modos de vida compartilhados socialmente ao longo de diversas gerações. Uma análise de releituras contemporâneas dessas narrativas precisa considerar a mudança de contexto em que essa história está inserida, ou seja, é preciso tratar da sociedade midiatizada em que esses processos comunicacionais estão imersos. Nesse sentido, nota-se a pertinência do conceito de midiatização (HEPP; HASEBRINK, 2015) para a questão.

"Quando argumentamos que em um processo de midiatização em curso nossas culturas e sociedades se transformam, como podemos investigar isso em detalhes?" (HEPP; HASEBRINK, 2015, p. 2) Ao considerar a midiatização como "(...) mudanças nas construções comunicativas de culturas e sociedades midiatizadas" (HEPP; HASEBRINK, 2015, p. 2), observa-se a relevância dos meios de comunicação nas sociedades contemporâneas ao auxiliar os indivíduos a compreender o mundo.

Ao tratar das tradições institucionalista e socioconstrutivista ${ }^{3}$
${ }^{3}$ A tradição institucionalista se direciona para estudos dos meios de comunicação de massa tradicional, enquanto a tradição socioconstrutivista investiga a mídia digital e a comunicação pessoal (HEPP; HASEBRINK, 2015). 

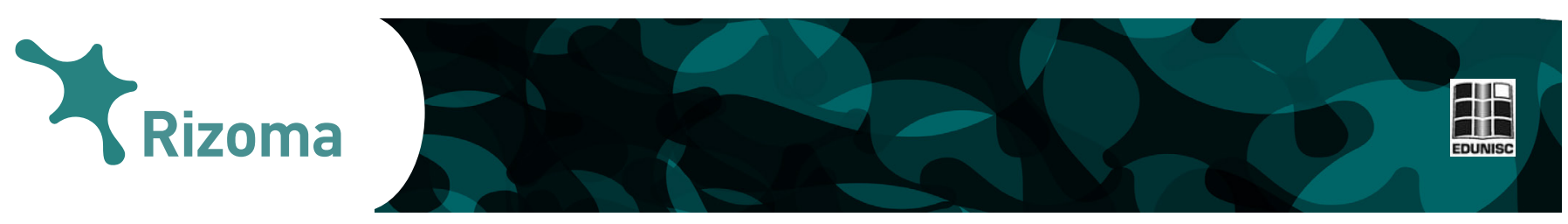

de midiatização, Hepp e Hasebrink (2015) ressaltam que o conceito de midiatização analisa a relação entre as mudanças das mídias e as transformações da cultura e da sociedade. Além disso, de acordo com a perspectiva socioconstrutivista, o mundo social é construído nas interações, que são responsáveis pela formação das culturas e das sociedades (HEPP; HASEBRINK, 2015).

Nesse sentido, é importante ressaltar que as pesquisas de midiatização se preocupam em investigar as mudanças nas interações sociais quando novas tecnologias estão imersas nesse processo (HEPP; HASEBRINK, 2015). Desta forma, o presente estudo se mostra como uma pesquisa de midiatização ao analisar as transformações das narrativas clássicas literárias, mudanças que resultam da migração da história para novos meios técnicos.

Esses novos suportes são potencializadores da reconfiguração das interações sociais e do surgimento de decodificações diferenciadas da história. Nota-se, portanto, que as interações investigadas nesse estudo se enquadram na interação social "à distância” (HEPP; HASEBRINK, 2015), pois os internautas de diversos lugares do mundo acompanham a web série pela internet, dialogando entre si e com os personagens.

Logo, ao investigar as interações sociais existentes na web série The Lizzie Bennet Diaries, observa-se que a midiatização complexificou os fluxos comunicativos (HEPP; HASEBRINK, 2015). A narrativa clássica da literatura, que antes era apresentada linearmente na progressão de leitura das páginas de um livro ou na exibição de episódios consecutivos de uma série televisiva, passa a ser oferecida como um jogo de quebra-cabeças que, para o entendimento completo da trama, precisa ser adequadamente montado.

As informações complementares nas diversas redes sociais, plataformas e sites possibilitam uma compreensão aprofundada da narrativa e dos anseios dos personagens. Além disso, os internautas podem agregar informações e "participar" da história, um tipo de imersão que antes não existia. A fim de investigar as mudanças nas construções comunicativas, que refletem nas transformações da cultura e da sociedade, o tópico a seguir discute o conceito de codificação/decodificação de Hall (2003), que auxilia na compreensão das diversas leituras existentes de uma mesma história.

\section{Decodificação dos clássicos na contemporaneidade: a perspectiva de análise do objeto empírico}

Hall (2003) aponta que o modelo linear de pesquisa em comunicação de massa (emissor/mensagem/receptor) foi bastante criticado por não dar conta da complexidade das relações dos sujeitos envolvidos nos fluxos midiáticos. Desta forma, o autor propõe pensar os processos comunicacionais a partir da articulação de momentos distintos, mas conectados: produção, circulação, distribuição/consumo, reprodução. "Isto seria pensar o processo como uma 'complexa estrutura em dominância', sustentada através da articulação de 
práticas conectadas, em que cada qual, no entanto, mantém sua distinção e tem sua modalidade específica, suas próprias formas e condições de existências" (HALL, 2003, p. 387).

Ao considerar o momento da produção/circulação, nota-se que as mensagens circulam dentro de determinados códigos, "regras de linguagem" (HALL, 2003, p. 388). É sob essa forma discursiva que o produto chega até o público almejado. Desta forma, ao ser concluída, a mensagem precisa ser decodificada para que seja compreendida e produza sentidos na vida dos leitores (HALL, 2003). Nesse processo, segundo Hall (2003), os momentos de "codificação" e "decodificação" se mostram como autônomos, sendo possuidores de características próprias. Assim, nenhuma dessas etapas do circuito garante a seguinte, pois os fluxos comunicacionais circulam em meio a ruídos e falhas de comunicação.

É importante ressaltar a importância da codificação, pois um fato "bruto" não pode ser veiculado em um meio de comunicação, como um acidente de grandes proporções em um telejornal, por exemplo. Logo, os fatos precisam ser transformados em discurso, seguindo regras específicas de linguagem (HALL, 2003). Nota-se a questão na releitura de clássicos literários, pois uma mesma narrativa precisa ser codificada de uma forma específica, considerando o meio em que será veiculada e para qual público se dirige. Hall (2003) nomeia esse momento como "forma-mensagem", que compreende a estrutura dos processos comunicacionais que serão desenvolvidos ao longo das relações entre os sujeitos imersos no sistema.

O início do circuito é na produção, momento em que se constrói a forma-mensagem. Nessa etapa de desenvolvimento, o discurso é influenciado por condicionantes internos (rotinas produtivas, ideologias da instituição, conhecimentos e competências profissionais) e externos (contexto econômico, cultural, social, político e geográfico) (HALL, 2003). Mesmo assim, o sistema construído como, por exemplo, a web série The Lizzie Bennet Diaries, não é fechado.

Observa-se que a circulação e a recepção também se mostram como momentos de produção, pois nessas etapas se tem a interação com o público, a qual afeta a produção. Portanto, nota-se que as etapas de produção (codificação) e recepção (decodificação) estão fortemente relacionadas, sendo instantes diferenciados de um mesmo processo comunicacional (HALL, 2003).

Antes que essa mensagem possa ter um "efeito" (qualquer que seja sua definição), satisfaça uma "necessidade" ou tenha um "uso", deve primeiro ser apropriada como um discurso significativo e ser significativamente decodificada. É esse conjunto de significados decodificados que "tem um efeito", influencia, entretém, instrui ou persuade, com consequências perceptivas, cognitivas, emocionais, ideológicas ou comportamentais muito complexas. Em um momento "determinado", a estrutura emprega um código e produz uma "mensagem"; em outro momento determinado, a "mensagem" desemboca na estrutura das práticas sociais pela via de sua decodificação. (HALL, 2003, p. 390). 


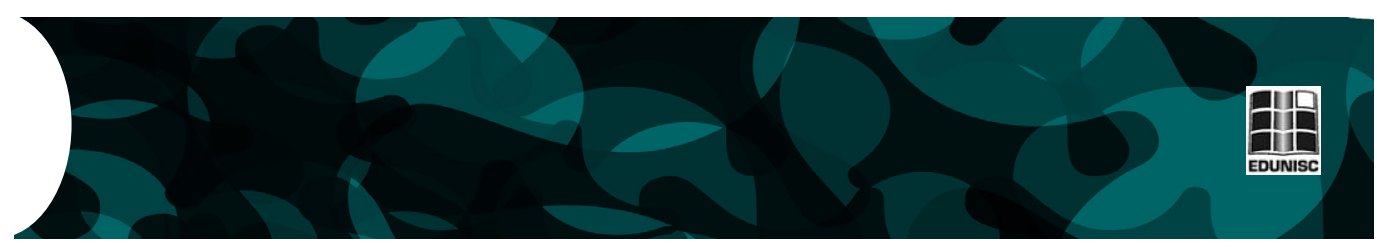

Desta forma, segundo Hall (2003), o grau de simetria entre os momentos de codificação e de decodificação influencia diretamente nos níveis de compreensão da mensagem. É importante ressaltar que a realidade é constantemente mediada pela linguagem (HALL, 2003). Portanto, “(...) não há discurso inteligível sem a operação de um código" (HALL, 2003, p. 392). Por exemplo, a fim de ler uma história codificada em russo, o leitor precisa dominar o código, ou seja, a língua russa. Ou para compreender uma reportagem, o público precisa compreender minimamente as características desse tipo de produção, reconhecendo-o como constituinte do gênero jornalístico.

Logo, ao acompanhar uma web série literária, o internauta também precisa ter conhecimento do código utilizado e das especificidades desse tipo de formato audiovisual, a fim de poder ter uma experiência completa na história. Ao considerar o objeto empírico analisado, observa-se que a trama da web série, que se trata de uma narrativa clássica literária, é desenvolvida em um discurso coerente imerso em um contexto específico.

Alguns condicionantes externos de produção da web série, como a proposta de uma releitura contemporânea e a nacionalidade dos criadores de The Lizzie Bennet Diaries (que é norte-americana), influenciaram diretamente na elaboração do código desse produto. Essas influências posteriormente foram decodificadas pelos receptores como, por exemplo, tem-se o deslocamento dos personagens para a atualidade, os atores jovens e as gírias utilizadas direcionam a produção para receptores adolescentes e, diferentemente da obra literária de origem inglesa, o acento na fala dos personagens e os locais em que se passa a história são norte-americanos.

Apesar dessas mudanças, nota-se, especialmente nas releituras contemporâneas de narrativas clássicas da literatura, que a estrutura básica da trama permanece, pois existem personagens com características específicas, relacionamentos, cenas e acontecimentos que o público espera encontrar ao se interessar pela história. Além disso, essa estrutura é fundamental para caracterizar determinada produção como releitura de determinado livro.

Hall (2003) coloca que alguns códigos são aprendidos tão cedo que logo parecem "naturais" em sua existência. Nesse sentido, nota-se que essas tramas percorrem os séculos de história humana, sendo profundamente naturalizadas na cultura da humanidade. "Na verdade, o que os códigos naturalizados demonstram é o grau de familiaridade que se produz quando há um alinhamento fundamental e uma reciprocidade - a consecução de uma equivalência - entre os lados codificador e decodificador de uma troca de significados" (HALL, 2003, p. 393). Desta forma, a proximidade que o público tem dessas histórias se refere diretamente ao domínio do código que, juntamente com a história de vida e visão de mundo do indivíduo, refletem na decodificação da "forma-mensagem".

A interpretação do mundo e dos acontecimentos exige o domínio de códigos para os diversos setores da vida em sociedade (cultural, social, econômico, político, etc). Desta forma, os indivíduos tendem a interpretar os discursos a partir de "sentidos dominantes ou preferenciais" (HALL, 2003), pois se trata do código profundamente naturalizado de determinado grupo. 

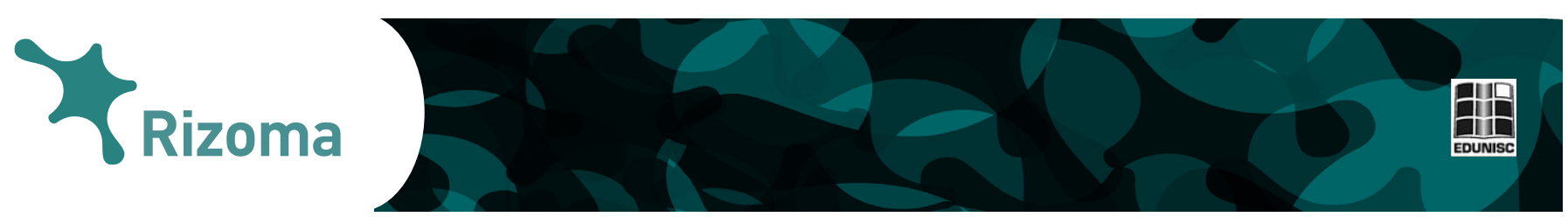

Os produtores dos meios de comunicação buscam eliminar ao máximo os mal-entendidos no momento de decodificação, a fim de que o público interprete a mensagem de modo mais próximo possível da intenção inicial do codificador (HALL, 2003).

"A menos que seja disparadamente aberrante, a codificação produz a formação de alguns limites e parâmetros dentro dos quais as decodificações vão operar. Se não houvesse limites, as audiências poderiam simplesmente ler qualquer coisa que quisessem dentro das mensagens" (HALL, 2003, p. 398). Portanto, a comunicação efetiva acontece a partir de certa reciprocidade entre os momentos de codificação e decodificação. Essa correspondência entre os códigos, de acordo com Hall (2003), não é natural, mas, sim, construída.

$\mathrm{O}$ autor propõe três posições de decodificação de discursos, que serão utilizadas na análise do objeto empírico desse estudo. Na primeira posição, hegemônica-dominante, o público opera dentro do código dominante. Nesse caso, o indivíduo decodifica a mensagem em consonância com a intenção original da codificação. Essas interpretações hegemônicas dependem da operação do código profissional: iluminação, escolha de imagens, enquadramentos (HALL, 2003).

Já a segunda posição se trata do código negociado, que “(...) reconhece a legitimidade das definições hegemônicas para produzir as grandes significações (abstratas), ao passo que, em nível mais restrito, situacional (localizado), faz suas próprias regras - funciona com as exceções à regra" (HALL, 2003, p. 401). Desta forma, a versão negociada funciona por meio de lógicas específicas, localizadas. Já diferentemente das posições anteriores, o código de oposição se realiza a partir de uma leitura de contestação. Nessa versão, os sujeitos decodificam a "forma-mensagem" de forma completamente contrária ao código hegemônico (HALL, 2003).

Ao considerar um produto comunicacional que tem alcance global, as diversas interpretações do objeto empírico analisado podem ser investigadas a partir da perspectiva da codificação/decodificação de Hall (2003) acima explicitada. Na próxima seção, serão observadas as diferentes possibilidades de decodificação da web série The Lizzie Bennet Diaries, a partir da análise de uma cena do episódio $84(U g h)$ e suas repercussões nos comentários do vídeo.

\section{Jane Austen no século XXI: decodificação da história de Orgulho e Preconceito em novos formatos}

Nos anos 1800, as mulheres precisavam de um "bom casamento" para atingir um status social vantajoso. Na trama original de Orgulho e Preconceito, de Jane Austen, a família Bennet não vive financeiramente bem. Em meio a bailes e visitas, a mãe tenta desesperadamente casar suas cinco filhas. Uma delas, Elizabeth Bennet, é a protagonista. Na narrativa, ela conhece o orgulhoso aristocrata Fitzwilliam Darcy, seu par romântico. Entretanto, antes de terminarem juntos, o casal passa por diversos acontecimentos que mudam seus preconceitos e visões de mundo (O LIVRO..., 2016). 

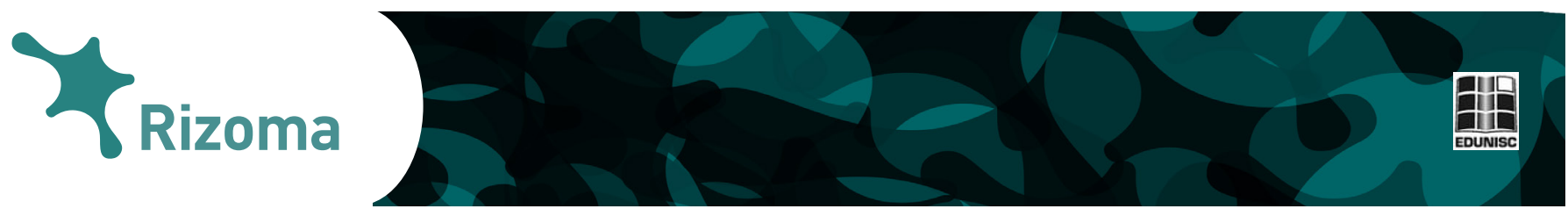

Ao longo dos séculos, a história original de Austen migrou para diversos suportes. Foram produzidas séries televisivas, filmes cinematográficos, peças teatrais e web séries. O objeto empírico desse estudo - a web série The Lizzie Bennet Diaries - é uma releitura contemporânea de Orgulho e Preconceito. Na história, a protagonista Lizzie Bennet é uma estudante de pós-graduação em Comunicação que possui um canal no YouTube e tem o costume de gravar vídeos contando sobre o seu cotidiano.

Veiculada de abril de 2012 a março de 2013, a web série conta com 100 episódios (em formato de $v \operatorname{logs}^{4}$ ) no canal no YouTube da personagem principal (Lizzie Bennet). Além disso, a história acontece em outras plataformas e suportes, pois cada personagem tem uma conta no Twitter, na qual interagem entre si e com os seguidores. Posts do Tumblr, vídeos em canais de personagens secundários (como o da irmã de Lizzie) e dois livros da série também fornecem informações complementares sobre a história.

Até o dia 12 de fevereiro de 2017, o canal no YouTube The Lizzie Bennet Diaries tinha mais de 268 mil inscritos. O primeiro $v \log$ da web série (My name is Lizzie Bennet), episódio em que a personagem se apresenta para o público, apresentava mais de 2 milhões e 600 mil visualizações. O episódio 84 (Ugh) analisado nesse artigo possuía mais de 800 mil visualizações até a presente data.

$\mathrm{Na}$ cena analisada do episódio, Lizzie conversa com Darcy quando recebe um telefonema avisando que sua irmã Lydia está em apuros. O namorado da irmã, George Wickham, ameaça divulgar um filme de sexo (sex tape) na internet. Na ocasião em que a web série foi veiculada pela primeira vez, os seguidores tinham acesso ao site em que seria divulgado o filme, local em que encontravam uma contagem regressiva para o dia em que o vídeo seria disponibilizado.
4 Vlog (abreviação de videoblog) se trata de uma produção audiovisual "amadora" direcionada para a publicação em canais pessoais do YouTube. São produções de baixo custo, que se estruturam no conceito de monólogo realizado diretamente para a câmera. Os vlogs são vídeos curtos e podem tratar de diversos assuntos, desde política até acontecimentos da vida cotidiana (BURGUESS; GREEN, 2009).

Figura 1 - Lizzie recebe más notícias enquanto conversa com Darcy

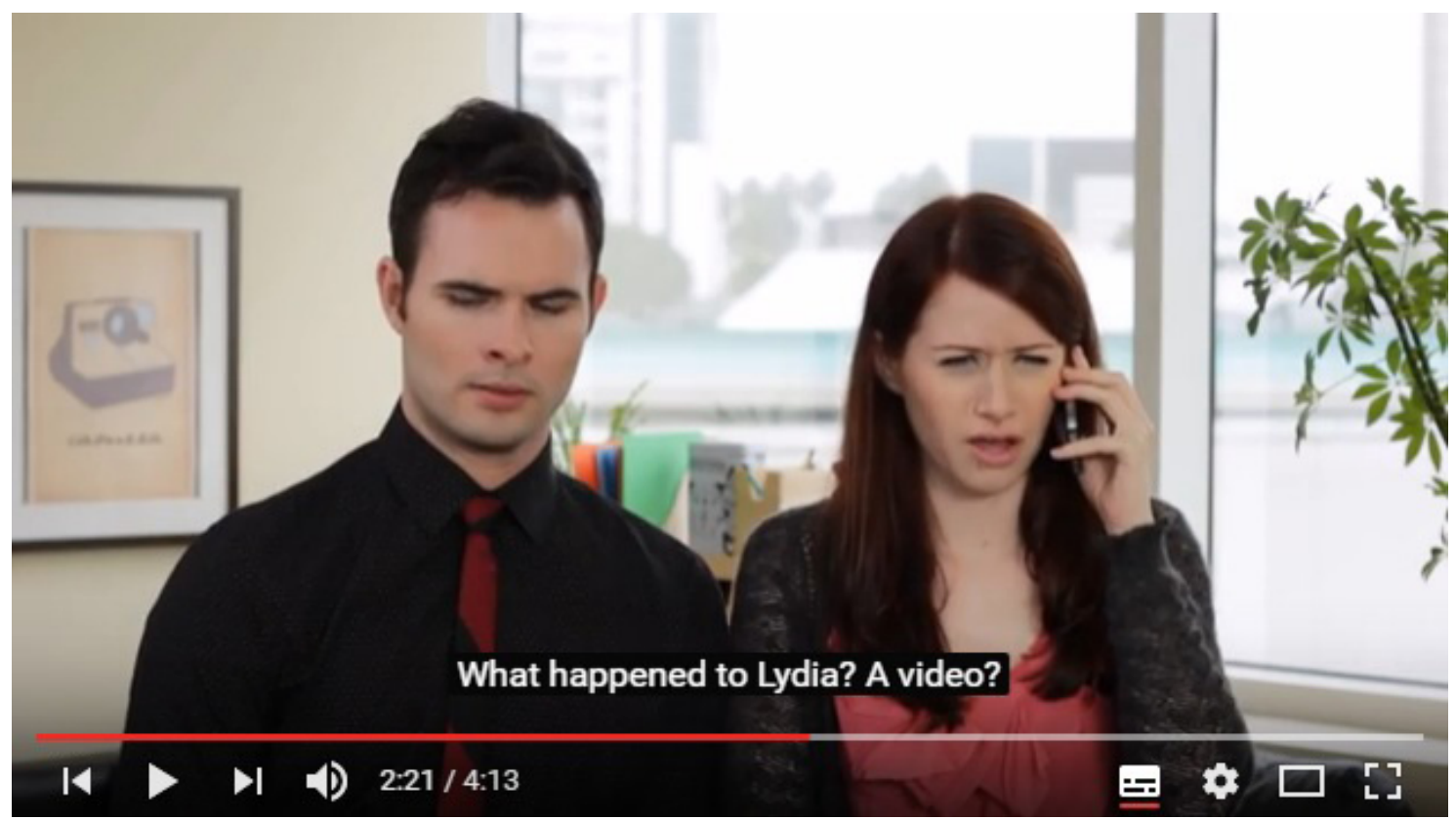

Fonte: DIARIES, The Lizzie Bennet (2013) 
Na história original de Austen, Wickham foge com Lydia. Na época, a fuga de moças solteiras significava um escândalo social de grande impacto. Na web série, não faria sentido manter a situação original, pois a história se passa na contemporaneidade, período em que a instituição do casamento se enfraqueceu ao longo dos anos. Desta forma, se Lydia fugisse com Wickham na web série, não seria uma situação tão indecorosa como no romance original. Logo, a divulgação da sex tape se mostra mais adequada no contexto atual, significando um escândalo de grande impacto.

Em ambos os casos, Lizzie fica horrorizada. No livro, Elizabeth fala sobre a situação da irmã: "Ela está perdida para sempre" (She is lost forever). Na web série, por sua vez, ela diz: "A internet é para sempre" (The internet is forever) (KELLEHER, 2015). Também nas duas situações, tanto no livro, como na web série, o grande herói que salva a irmã de Lizzie é Darcy. No livro, o mocinho fornece o dinheiro exigido para que Wickham se case com Lydia. Na web série, Darcy derruba o esquema perverso de Wickham ao comprar a empresa responsável pelo site em que seria divulgada a sex tape. Ao considerar a manutenção da estrutura básica de uma história clássica, observa-se que a ação de Darcy é esperada pelo público e é um momento que auxilia na aproximação de Darcy e Lizzie.

Esse episódio contou com 4.523 comentários até o dia 12 de fevereiro de 2017. A partir de uma pesquisa exploratória, observou-se que grande parte da participação dos seguidores comentou sobre a relação entre Darcy e Lizzie - os olhares e sorrisos que estreitam o surgimento do romance. Outros comentários negativos tratavam da conduta de George Wickham, como: "É possível odiar um personagem ficcional com todo o seu ser? Porque eu odeio" . Nota-se nesses exemplos a decodificação hegemônica-dominante da trama, na qual os seguidores esperam pela ação do herói que culminará no final feliz. Observa-se que essa interpretação é a esperada pelos produtores da série, que construíram a história a partir da estrutura do romance original.

Entretanto, a web série tem como proposta uma imersão profunda do internauta na história, pois ele pode dialogar com os personagens, além de acompanhar seu cotidiano, pensamentos e anseios. Desta forma, a participação do público é potencializada. Kelleher (2015) assinala um comentário que demonstra uma decodificação de oposição àquela dominante citada acima: "E se... são os fãs que ajudassem a derrubar o site e "salvar" Lydia? Certamente, entre milhares de nós, há alguns que sabem como fazer um ataque $\mathrm{DoS}^{6}$ em um site"

Na história, o meio online ocasionou uma decodificação diferente da dominante, apontando uma percepção do seguidor de que ele poderia participar mais efetivamente da trama. Esse comentário específico não modificou a narrativa planejada de antemão pelos produtores. Entretanto, ele aponta para diferentes possibilidades de leitura de uma história, principalmente em produções para a internet, nas quais o público está muito mais próximo da experiência narrativa.

Além disso, o site Pemberley Digital tem feito experimentações que se direcionam para a potencialização da participação do internauta em suas
5 No original: "Is it possible to hate a fake person with all of your being? Because I do".

6 Conhecido como DoS Attack, trata-se de um ataque de negação de serviços, ou seja, um ataque para sobrecarregar o computador

e impedir que ele execute suas tarefas (ALECRIM, 2012). Nesse caso, o comentário se refere ao site em que Wickham divulgará a sex tape, apontando a possibilidade de que os próprios seguidores fossem os heróis, impedindo o sistema de realizar a veiculação do vídeo.

7 No original: "What if... it's the fans who help take the site down and 'save' Lydia? Surely, among thousands of us, there are some... who know how to do a DOS attack on a site". 

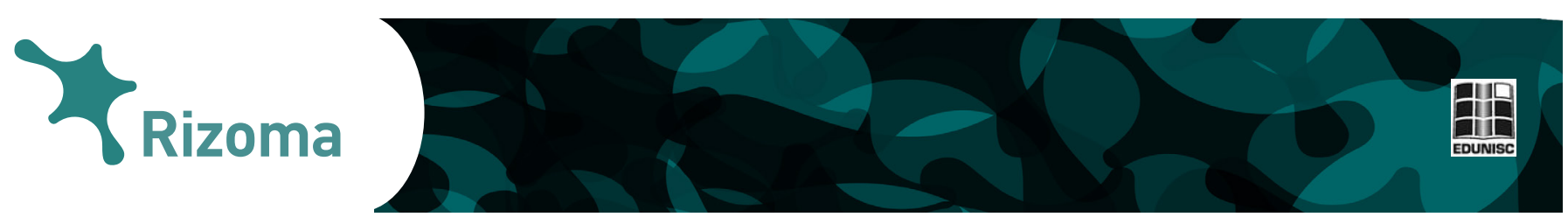

produções. Em The Lizzie Bennet Diaries, após a conclusão da série, os personagens principais (Lizzie e Darcy) gravaram dois vídeos de perguntas e respostas, respondendo aos questionamentos dos seguidores, ávidos por saber do futuro do casal.

O site norte-americano também produziu em 2013 a web série Welcome to Sanditon, baseada em uma novela inacabada de Jane Austen. Nessa produção, os usuários tinham como possibilidade se tornar moradores da cidade virtual de Sanditon, transformando-se em personagens da história. Os internautas podiam gravar seus vídeos por meio de um aplicativo criado exatamente para esse fim. Algumas produções do público foram selecionadas para fazer parte dos episódios principais da série.

\section{Considerações finais}

As experiências do site Pemberley Digital, em específico na web série analisada nesse estudo (The Lizzie Bennet Diaries), revelam a potencialidade de imersão do público nessas histórias criadas com perspectiva interativa, nas quais os internautas podem conversar com seus personagens favoritos e opinar sobre as ações e decisões tomadas ao longo da trama.

Observou-se que a imersão na narrativa possibilitou diferentes decodificações da história, mostrando a partir dos comentários, a existência do desejo do público em participar da ação, tornando-se também um personagem. Além da posição hegemônica-dominante apresentada em grande parte dos comentários, nos quais os internautas "torciam pelo mocinho" e repudiavam o vilão, encontrou-se também uma decodificação de oposição, na qual o seguidor propunha que o próprio público assumisse o papel do mocinho Darcy, tendo uma função ativa na história.

Ao refletir sobre esses processos de midiatização, nota-se que as mudanças nas construções comunicativas, a partir do uso de diferentes suportes e meios técnicos, refletem nas transformações da cultura e da sociedade (HEPP; HASEBRINK, 2015). Nesse contexto, as narrativas clássicas acompanham essas mudanças, podendo ser decodificadas diferentemente em cada época em que são reapropriadas, agregando especificidades do tempo em que se encontram no momento e repercutindo nos sujeitos sentimentos e angústias da condição humana.

\section{Referências}

ALECRIM, Emerson. Ataques DoS (Denial of Service) e DDoS (Distributed DoS). Disponível em: $<$ https://www.infowester.com/ddos.php >. Acesso em 20 mar. 2017.

BARBOSA, Marialva. O presente e o passado como processo comunicacional. Matrizes, São Paulo, v. 5, n. 2, 2012, p. 145-155. Disponível em: <http:// 

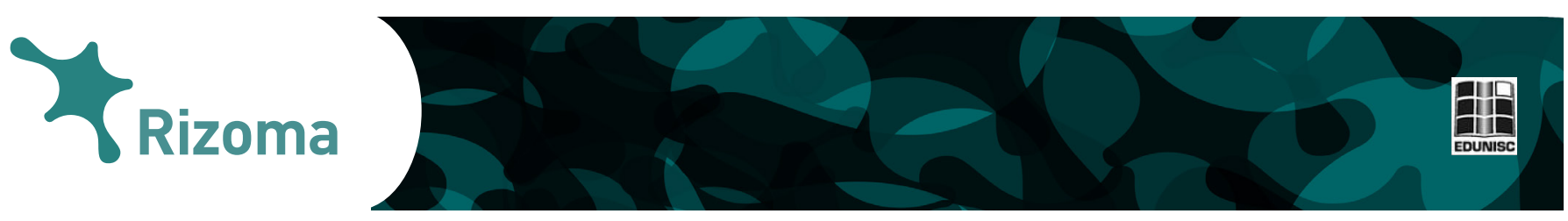

www.revistas.usp.br/matrizes/article/viewFile/38330/41187>. Acesso em: 10 abr. 2017.

BURGUESS, J.; GREEN, J. YouTube e a Revolução Digital: como o maior fenômeno da cultura participativa está transformando a mídia e a sociedade. São Paulo: Aleph, 2009. 239 p.

CALVINO, Italo. Por que ler os clássicos. São Paulo: Companhia das Letras, 2007. 285 p.

EPLEY, Robin. 7 Literary Web Series you should be watching based on your favorite book. Disponível em: <http://www.bustle.com/ articles/98948-7-literary-web-series-you-should-be-watching-based-onyour-favorite-book>. Acesso em: 20 mar. 2017.

HALL, Stuart. Codificação/Decodificação. Da diáspora: identidades e mediações culturais. Belo Horizonte: EDUFMG, 2003. p. 387-406.

HEPP, A.; HASEBRINK, U. Interação humana e configurações comunicativas: transformações culturais e sociedades midiatizadas. Revista Parágrafo, São Paulo, v. 3, n. 2, 2015, p. 75-89. Disponível em: <http:// revistaseletronicas.fiamfaam.br/index.php/recicofi/article/view/333/341>. Acesso em: 05 abr. 2017.

KELLEHER, Julie Salmon. What Jane Austen can teach us about our new internet selves (audiovisual). 2015. Produção: TEDx Talks. Exibição: TEDxWWU, 2015. Duração: 15'35". Disponível em: <https://www. youtube.com/watch?v=2VBs8Oqbw3k>. Acesso em 04 abr. 2017.

O LIVRO da Literatura. Organização James Canton... [et al.]. São Paulo: Globo, 2016. 352 p.

UGH - Ep: 84. Disponível em: <https:/www.youtube.com/watch?v=k90q Mr3Sstg\&index=135\&list=PL_ePOdU-b3xcDyyzeR5NjxeLEElsqYzn1>. Acesso em: 11 mar. 2017. 